\title{
Methodological basis for the development of the rating system for assessing the energy efficiency of the industrial facilities
}

\author{
Natalia Shchepkina* \\ Moscow State University of Civil Engineering, Yaroslavskoe shosse, 26, Moscow, 129337, Russia \\ Funding: The reported study was funded by RFBR, project number 20-010-00754
}

\begin{abstract}
Nowadays, there is a key problem in the development of energy conservation and energy efficiency in the Russian Federation. It is the absence of the system for assessing energy efficiency of the largest ultimate customers of the energy resources, they are industrial facilities. We can speak about the existence of the methods for classifying residential buildings or equipment as energy efficient. We can also speak about the absence of the methods for assessing the energy efficiency of the industrial facilities in both foreign and Russian practice nowadays. The methodological basis for the development of the rating system for assessing the energy efficiency of the industrial facilities is discussed in this article. The fundamental principles are presented in it. They must be taken into account when developing the rating system. The structural and logical scheme for the development of the rating system for assessing the energy efficiency of the industrial facilities is proposed. It reflects the relationship and sequence of its main elements, and it allows presenting the development process in the complete form.
\end{abstract}

\section{Introduction}

The problem of energy saving and energy efficiency is relevant for the overwhelming majority of economic entities associated with energy-intensive production processes. The high share of costs for the energy resources in the structure of costs for the production of the industrial products requires their constant monitoring.

The global trend in the efficient use of the energy resources and the use of the renewable energy technologies is associated with the depletion of the non-renewable natural resources and the environmental aspects of energy production.

Nowadays the industrial sector currently accounts for about a third of the world's final energy consumption and carbon dioxide equivalent emissions. Despite the serious consequences for the economy of the COVID-19 pandemic, the high growth rates remain in this sector [1]. According to the forecasts, they will increase the growth of the world economy by $88 \%$ by 2050 [2]. At the same time, the organizational and economic measures to improve energy

* Corresponding author: SchepkinaNN@gic.mgsu.ru 
efficiency based on existing technical solutions can provide a $30 \%$ reduction in the energy consumption in the industrial sector globally. The use of the promising technological innovations can provide a $60 \%$ reduction [1].

In order to draw the attention of the industrial sector to such cost-effective opportunities, the United Nations Economic Commission for Europe has developed a draft industrial energy efficiency action plan in 2020. Within its framework, the primary task is to formulate clearly what is meant by energy efficiency in the industry and what are its ,non-energy” benefits for the enterprises. The key obstacle to investment in industry's energy efficiency is the lack of the adequate methodological development to measure the energy savings achieved through the implementation of the energy efficiency projects [3].

At the present stage, considerable attention is paid to the optimization of energy costs at all levels of Executive and legislative power of the Russian Federation, which is reflected in various forms of economic and energy foresights. As noted in the energy Strategy 2035: "the development of energy saving and energy efficiency in the energy consumer sectors is one of the key scenario conditions in forecasting the prospects for the development of the fuel and energy sector". It is planned to "reduce the energy intensity of GDP by 1.3-1.5 times (or in the amount of 315 - 580 million tons of conventional fuel per year)" due to the structural restructuring of the Russian economy and the rapid growth of non - energy-intensive industries of manufacturing, construction, services (with a corresponding decrease in the share of raw materials and energy-intensive industries by 3-4 percentage points by 2035), as well as due to technological modernization and development [4].

However, in the current period, the key problems that limit the ability to achieve the goal of the current State program of the Russian Federation "Energy Development" to reduce the energy intensity of the gross domestic product are associated with the lack of methodological tools to determine the level of energy efficiency of economic entities [5].

Currently, there is no reliable information on energy efficiency of economic facilities in the required amount, methods and criteria for its systematization to ensure effective energy management have not been developed. These facts are considered as key in setting the objectives of the study.

The systematization of the energy efficiency indicators, labeling systems and energy efficiency scales for the objects of assessment in the United States, European Union countries, CIS countries made it possible to conclude that there are methods for classifying residential buildings or equipment as energy efficient. There are no methods for assessing energy efficiency classes of the industrial facilities in foreign practice [6-11]. This aspect showed the relevance of the theme not only for the Russian Federation, but also for the other countries of the world.

The rating systems are widely used in the developed countries in the modern conditions. They are used to assess the quality of the design and construction solutions for buildings according to the criteria of energy efficiency, ecology, comfort, and resource conservation. We can note the most popular global rating systems. They are the American one - LEED (The Leadership in Energy and Environmental Design), English one - BREEAM (Building Research Establishment Environmental Assessment Method), German one - DGNB (Deutsche Gesellschaft für Nachhaltiges Bauen).

The rating systems are actively used in the energy sector in the international practice. They are also applied in the field of energy efficiency, for comparing some subjects (the regions or the cities of the different countries). Among such rating systems it is worth noting: the Energy Efficiency Rating of the RF Subjects (EERRFS), the US State Energy Efficiency Scorecard (SEES), the US Cities Energy Efficiency Scorecard (CEES), the Austrian Federal Lands Energy Transformation Index (BEX), Baden-Württemberg County Energy Efficiency Competition (WLEBW), Energy Efficiency Index of 15 Largest Cities in Spain (EEISLC). 
The aim of this study is to form the methodological basis for the development of the rating system for assessing the energy efficiency of the industrial facilities.

Achieving this goal is possible by solving the following tasks:

- To formulate the main principles which must be taken into account when developing the rating system for assessing the energy efficiency of the industrial facilities.

- To provide the structural and logical scheme for the development of the rating system for assessing the energy efficiency of the industrial facilities.

The object of this study are industrial facilities, which are considered as a property complex, including industrial buildings and structures with all communications and adjacent infrastructure.

The subject of the study is the methods and approaches to the grouping of industrial facilities on the basis of the identified common classification signs of energy efficiency.

The problem is the lack of methodology that allows you to classify industrial facilities according to the efficiency of using energy resources to form a database on energy consumption, energy intensity and the policy of energy saving and improving the energy efficiency of the industrial facilities and enterprises in general. The solution to the stated problem is based on forming the tools for assessing the level of energy efficiency of the industrial facilities and determining the energy efficiency class.

In the global space, energy efficiency issues in various industries are considered by such researchers as Mengmeng $\mathrm{Xu}$, Boqiang Lin, Siquan Wang [12], J. Malinauskaitea, H. Jouharab, L. Ahmadb, M. Milanic, L. Montorsic, M. Venturellic [13], Salman Haidera, Mohd Shadab Danishb, Ruchi Sharmab [14], Mokhtara, M. Nasootib [15]. It is worth noting that the foreign scientists' research in the field of energy saving and energy efficiency has a narrow focus. Each of the authors presented the problems of energy efficiency in the particular industry. The research lacks a comprehensive approach across all the industries. This circumstance indicates the relevance of the issue of assessing the energy efficiency of the industrial facilities both for the Russian Federation and abroad.

Among the domestic developments in the field of energy efficiency in industry, it is worth noting the works of Verstina N. G., Meshcheryakova T. S., Solopova N. A., Taskaeva N. N., Shchepkina N. N. [16-17]. These authors investigate the problems of monitoring the energy efficiency of the industrial facilities.

Taking into account the facts presented above, which state that there are no methods for assessing the energy efficiency of the industrial facilities in both foreign and Russian practice, this study considers forming of the methodological basis for developing the rating system for evaluating the energy efficiency of the industrial facilities. The development of the rating system is aimed at classifying the industrial facilities according to the level of energy efficiency. It is necessary to solve the most important state tasks in the field of energy conservation and energy efficiency.

\section{Materials and Methods}

All the rating systems are formed according to the conceptual similar principle which is shown in Figure 1. 


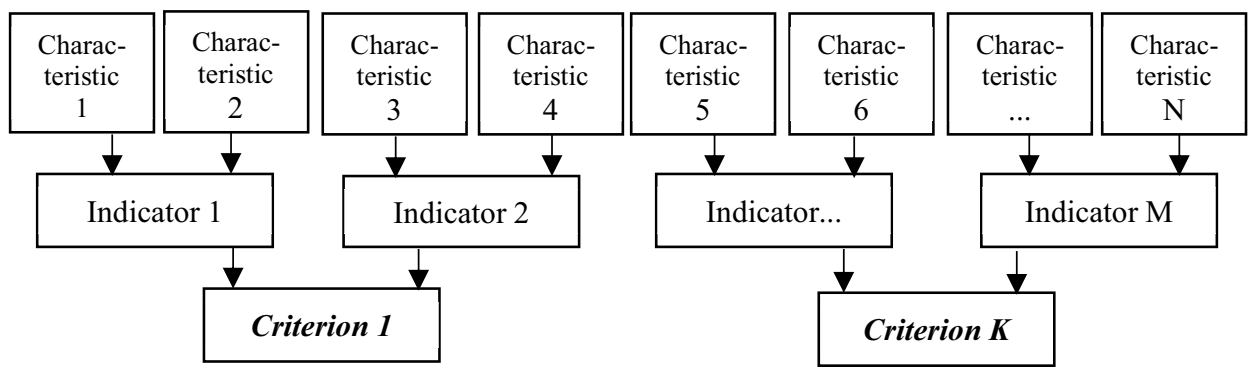

Fig. 1. Conceptual scheme for forming of the rating system of evaluation.

The presented scheme is used in the different variations in the world rating systems for energy efficiency. There are only indicators in some rating systems, there are characteristics and indicators in the other rating systems, and you can also meet characteristics, indicators, criteria in them.

The indicators which are thematically grouped into groups of criteria are based on the assessment of a large number of qualitative and quantitative indicators. The weight values for the criteria will be determined based on the expert opinion. Different weights for criteria are set through the peer review. In most cases, the indicators are based on the country's legal and regulatory framework.

We'll present the methodical principles of the development of the rating system for assessing the energy efficiency of the industrial facilities.

\section{Results}

Within the framework of the study, the category ,industrial object" is used as an object of energy efficiency assessment. We mean a set of industrial buildings, structures which are separate geographically and interconnected organizationally and technologically, equipped with energy-consuming equipment and ensuring the continuity of the technological cycle of the industrial production here. The industrial enterprise may include one or more industrial facilities. The industrial enterprise is considered as a property complex intended for the implementation of the entrepreneurial activities in the field of industry.

Energy efficiency is the basic principle of forming the rating system for evaluating the energy efficiency of the industrial facilities. The industrial enterprises, meeting their needs for energy resources necessary to ensure the continuity of the technological cycle of the industrial production, should strive to reduce energy consumption by implementing economic measures to improve energy efficiency based on existing technical solutions or using promising technological innovations.

The energy efficiency of the industrial facilities in the rating system is supposed to be evaluated by the combination of two basic categories: the energy efficiency of the buildings and the energy efficiency of the technological process. The separate group of criteria that define it, in its turn, represents each category. The sum of the scores according to the criteria determines the score value of the category as a whole. The weight of the indicators (points) is determined based on the expert opinion. Based on the maximum total score in the rating system of assessment, the share significance of each category of assessment in the integral value of the energy efficiency of the industrial object is determined.

As experts, it is planned to involve the leading Russian specialists in the field of energy saving and energy efficiency from the professional communities and specialized departments of the educational institutions: Non-profit Partnership „Engineers in Heating, Ventilation, Air Conditioning, Heat Supply and Building Thermal Physics” (NP „ABOK”), Association 
of Energy Service Companies (RAESCO), Moscow Power Engineering Institute (MPEI), etc.

When forming the rating system for energy efficiency of the industrial facilities, the following provisions should be taken into account:

1. The quantitative assessment of most indicators (characteristics) is made on the basis of the regulatory framework of the Russian Federation.

2. The parameters for some indicators are determined based on the expert opinion of the leading Russian experts in the field of energy saving and energy efficiency.

3. The rating assessment is made for the existing industrial facilities operating on the territory of the Russian Federation.

4. The general rating system includes 2 levels of rating:

- Energy efficiency rating of the buildings.

- Rating of the energy efficiency of the technological process.

5. The rating system is focused on achieving the high final indicators of the energy efficiency of the industrial facilities.

6. The significance of the categories and the weight of the indicators can be adjusted for different groups of the All-Russian Classifier of Economic Activities (ARCEA), depending on the type of economic activity of the industrial enterprise.

7. The energy efficiency class is assigned to the industrial facility on the basis of the general (integral) assessment.

Figure 2 shows the structural and logical diagram of the development of the rating system for assessing the energy efficiency of the industrial facilities. 


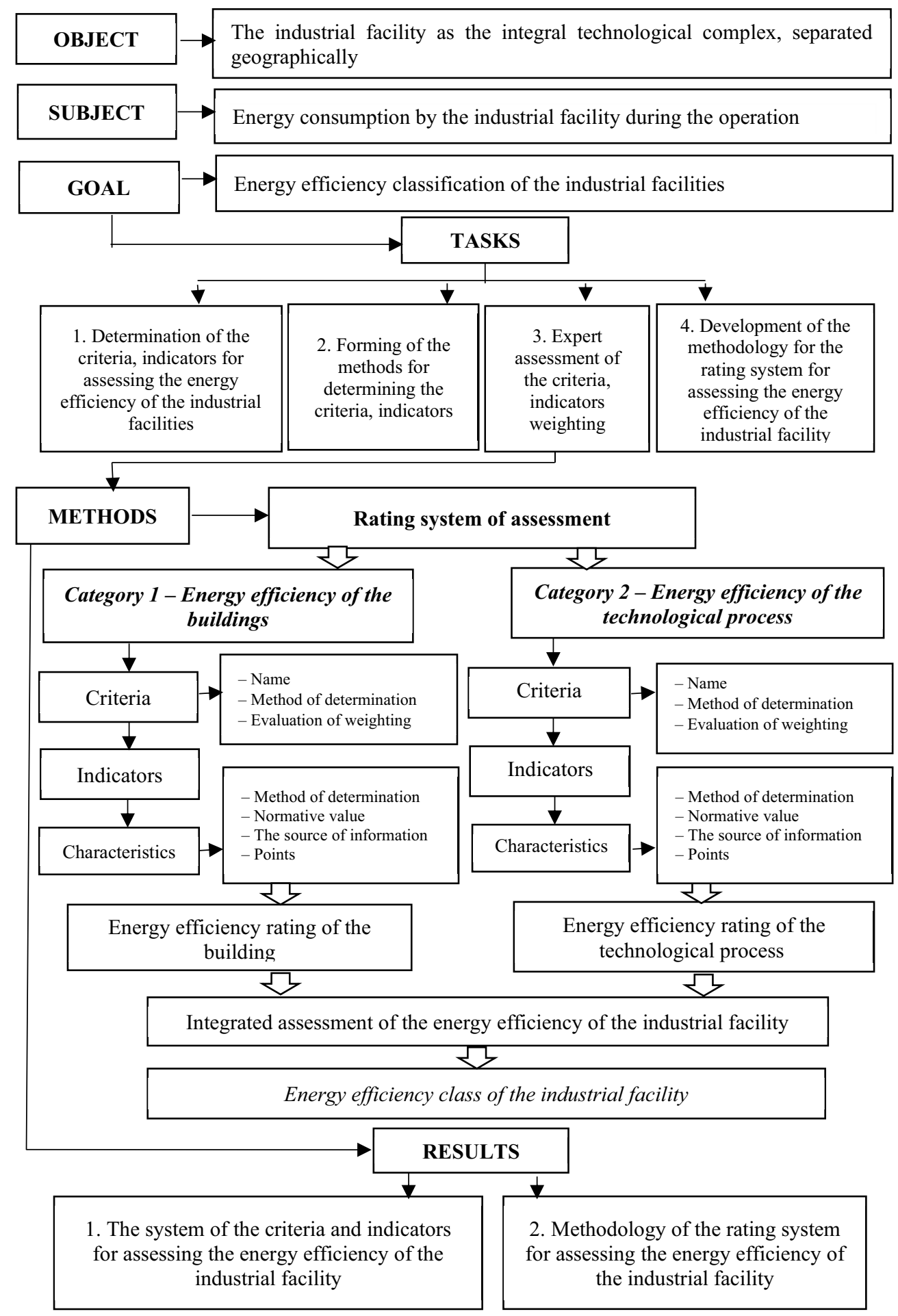

Fig. 2. Structural and logical diagram of the development of the rating system for assessing the energy efficiency of the industrial facility. 
When developing the rating assessment methodology, it is planned to use two groups of the indicators: technical indicators and organizational indicators. It is proposed to use monitoring of energy consumption in dynamics, goal-setting in the field of energy saving, implementation of energy management, financing of energy-saving measures, popularization of energy-saving lifestyle as criteria of the organizational group of indicators.

The rating system assesses the energy efficiency of the industrial facility according to the criteria which are grouped into the categories. Each of the criteria is expressed by one or by a group of indicators. Each of the indicators has its own numerical definition in the form of the characteristic, which corresponds to the point equivalent of the assessment. The criterion is assessed according to the point equivalent of the indicator characterizing it. The methods of determining the indicators, sources and the methods of obtaining initial data are determined with reference to the regulatory legal acts for each of the evaluation criteria. The sum of the points of all the categories determines the total (integral) value of the energy efficiency of the industrial facility. Depending on the amount of the points, the energy efficiency class is assigned to the industrial facility.

If it is necessary, the system of the basic indicators can be adjusted by the coefficients or supplemented by the indicators, depending on the ARCEA group to which the discussed industrial enterprise belongs.

\section{Discussion}

Among the existing methodological developments in the field of energy saving and energy efficiency, it is worth noting the methodology for the comprehensive assessment of the efficiency of the use of fuel and energy resources at the industrial enterprises. Belarusian team of authors developed it. This methodology makes it possible to assess the efficiency of the use of fuel and energy resources by the enterprise comprehensively and the achieved level of efficiency of energy consumption in comparison with the leading representatives of this industry, producing the similar products. It contributes to the determination of the rating assessment of industrial enterprises by the government bodies from the point of view of the efficiency of spending energy resources [18].

It is also worth mentioning the rating system for assessing the sustainability of the habitat, developed in the Russian Federation, used for the residential and public buildings, which are assessed according to 46 criteria of environmental, economic and social efficiency, grouped into 10 categories. The rating system for assessing the sustainability of the human habitat meets the goals of the present generation in meeting their needs in comfortable living environment and performing public functions through the use of the residential and public buildings without reducing the level of such an opportunity for the future generations [19]. Nowadays the Russian Federation has developed the methodology for determining the energy efficiency class of operated residential apartment buildings [20].

At the same time, there is currently no methodological tools that can be used as a basis for the classification of the most energy - intensive economic entities-industrial facilitiesaccording to the level of energy efficiency. Such a tool in the energy management system should meet the requirements of modernity and combine general development trends and the fundamental basis for managing economic systems, legislative acts, as well as it is necessary to take into account the best world developments.

\section{Conclusion}

Due to the lack of methodological developments for assessing the energy efficiency of the industrial facilities in Russian and world practice, the formation of the methodological basis 
for developing the rating system for assessing the energy efficiency of the largest energy consumers is considered within the framework of this study. These are industrial facilities. The study presents the main methodological principles that must be taken into account when developing such a rating system. The proposed structural and logical scheme for the development of the rating system for assessing the energy efficiency of the industrial facilities reflects the relationship and sequence of its main elements and allows you to present the development process in the integral form. The rating system for assessing the energy efficiency of the industrial facilities is being developed with the aim of classifying them according to the level of energy efficiency. Classification of industrial facilities by energy efficiency will give the opportunity to determine the priority of the object when solving state important tasks, including in the field of subsidies and crediting of measures to reduce energy intensity and optimize energy costs, to develop and implement alternative technologies with low energy intensity, as well as create an essential component financial planning at the macro and meso levels.

The scientific significance of the rating system for assessing the energy efficiency of the industrial facilities is to develop methodological tools for determining the level of energy efficiency of industrial facilities, their distribution into classes based on comparing the actual level of energy efficiency with a reasonable criterion and taking into account the type of economic activity.

Given the content of the passport of the Energy Saving and Improving Energy Efficiency subprogram of the state program of the Russian Federation Energy Efficiency and Energy Development, it can be concluded that the classification of industrial facilities can become part of the state-important system of program-targeted tools in the field of energy saving and energy efficiency.

Technique focused on industrial facilities, as the largest end-users of energy resources. At the same time, the general methodological approach to assessing the energy efficiency of industrial facilities can be extended to other economic entities when finalized, taking into account the specifics and scale of their business activities, and the peculiarities of the formation of the property complex.

Practical implementation of the rating system for assessing the energy efficiency of the industrial facilities will accelerate the solution of state tasks, including substantiating the transfer of the most energy-intensive facilities to alternative energy sources, will ensure the implementation of the internal policy of energy saving and energy efficiency, including using the energy management system according to ISO 50001, as well as the implementation of energy saving measures the volume and sources of their financing, the resulting effect or unrealized potential for energy saving.

The reported study was funded by RFBR, project number 20-010-00754.

\section{References}

1. Draft Industrial Energy Efficiency Action Plan, and assessment of the role of the United Nations Economic Commission for Europe in delivering on it, 22-23 September 2020, Geneva (2020)

2. Background paper on the Concept Note and Terms of Reference for the Task Force on Industrial Energy Efficiency in the United Nations Economic Commission for Europe (ECE) Region for 2019-2020, 26-27 September 2018, Geneva (2018)

3. Overcoming barriers to energy efficiency investment, The United Nations (2017)

4. Order of the Government of the Russian Federation No. 1523-r of 09.06.2020 (2020) 
5. Decree of the Government of the Russian Federation of March 28, 2019 №335 (2019)

6. Vereinheitlichung des Energieeinsparrechts für Gebäude und zur Änderung weiterer Gesetze (2020)

7. Existing systems of energy certificates of buildings in the world. UNDP / GEF project "Improving Energy Efficiency in the housing construction sector of Turkmenistan", Ashkhadab (2016)

8. Of the Energy Policy Act, from U.S. Government Publishing Office (GPO), (2005)

9. Comparative review of building energy efficiency standards and technologies in the United Nations Economic Commission for Europe region, Geneva (2018)

10. ISO 52003-1:2017 «Energy performance of buildings - Indicators, requirements, ratings and certificates - Part 1 (2017)

11. ISO/TR 52003-2:2017 Energy performance of buildings - Indicators, requirements, ratings and certificates - Part 2 (2017)

12. Mengmeng Xu, Boqiang Lin, Siquan Wang, Energy, 216, 119255 (2021)

13. J. Malinauskaitea, H. Jouharab, L. Ahmadb, M. Milanic, L. Montorsic, M. Venturellic, Energy, 172, pp. 255-269 (2019)

14. S. Haidera, M. S. Danishb, R. Sharmab, Energy Economics, 81, pp. 454-464 (2019)

15. Mokhtara, M. Nasootib, Energy Strategy Reviews, 28, 100458, March (2020)

16. N. Verstina, N., T. Meshcheryakova, N. Shchepkina, IEEE Xplore, 9271373 (2020)

17. N. Solopova, T. Meshcheryakova, N. Shchepkina, IOP, 869, 6 (2020)

18. T. M. Roman'kova, M. N. Grinevich, O. V. Golushkova. Energy efficiency of the enterprise: indicators, factors and mechanism of increase: monograph, Mogilev, Belorussiian-Russian university (2013)

19. Habitat sustainability rating system, Standard of organization National Association of Builders 2.35.4-2011 (2011)

20. Order of the Ministry of Construction of the Russian Federation "On Approval of the rules for determining the energy efficiency class of apartment buildings", 06.06.2016, $\mathrm{N}$ 399 / pr (2016) 